Jurnal METTEK Volume 5 No 2 (2019) pp 84-89

ISSN 2502-3829

ojs.unud.ac.id/index.php/mettek

\title{
Pengaruh Penggunaan Cascade Straight Heat Pipe Terhadap Temperatur Kerja CPU
}

\author{
( Wayan Gede Widyantara") \\ ${ }^{1)}$ Program Studi Teknik Mesin Universitas Udayana \\ Kampus Bukit Jimbaran, Badung, Bali, Indonesia 80361 \\ Email: yanwidi17@gmail.com \\ doi: https://doi.org/10.24843/METTEK.2019.v05.i02.p04
}

\begin{abstract}
Abstrak
Seiring perkembangan jaman, kebutuhan manusia akan komputer sangatlah tinggi. Berbagai aktivitas manusia sekarang mulai mengarah kepada penggunaan komputer. Kalo kita cari artinya, komputer itu adalah alat yang digunakan untuk melakukan pengolahan data. Kadangkala dalam penggunannya komputer mengalami permasalahan yang diakibatkan penggunaan yang berlebihan yang menyebabkan komputer panas sehingga sering terjadi yang namanya lag. Panas ini harus segera dibuang agar tidak merusak komponen hardware lainnya. Sistem pendinginan untuk CPU mulai mengarah pada penggunaan pipa kalor sebagai pendingin. Pipa kalor ini dapat mengatasi panas yang ditimbulkan oleh CPU yang nantinya akan membantu mengembalikan performa dari CPU tersebut. Pendinginan dengan menggunakan pipa kalor dilakukan secara cascade atau bertingkat. Cascade straight heat pipe pada pengujian kali ini terdiri dari single kondensor dan double kondensor yang sama-sama diberikan pembebanan 10 watt, 20 watt, 30 watt, 40 watt dan 48 watt. Pembebanan ini mewakili kondisi CPU saat diberikan beban kerja. Hasilnya cascade straight heat pipe double kondensor sangat memberikan pengaruh yang besar terhadap penurunan temperatur kerja CPU. Terbukti pada pembebanan 48 watt, double kondensor cascade straight heat pipe mampu menurunkan suhu hingga $64,06^{\circ} \mathrm{C}$
\end{abstract}

Kata Kunci : Pendinginan komputer, pipa kalor, pipa kalor bertingkat

\begin{abstract}
Undeniably, the human need for computers is very high. Various human activities are now beginning lead to the use of computers. If we look for the meaning, the computer is a tool used for data processing. Sometimes in the use of computers get problems caused by excessive use that causes the computer to heat up so that it often happens that the name lag. This heat must be removed immediately so as not to damage other hardware components. Today's era, the cooling system for the CPU starts to lead to the use of heat pipes as coolants. This heat pipe can overcome the heat generated by the CPU which will help restore the performance of the CPU. Cooling by using heat pipes is done in a cascade or multilevel manner. The Cascade straight heat pipe in this test consisted of a single condenser and a double condenser which were both given 10 watts, 20 watts, 30 watts, 40 watts and 48 watts of load. This load represents the CPU condition when given a workload. The result is a double condenser cascade straight heat pipe which has a great influence on reducing CPU working temperature. Evidenced by the 48 watt load, the double condenser cascade straight heat pipe can reduce the temperature to $64.06^{\circ} \mathrm{C}$
\end{abstract}

Keyword : Computer cooling, heat pipe, cascade straight heat pipe

Penulis korespondensi,

Email: yanwidi17@gmail.com 


\section{PENDAHULUAN}

Seiring perkembangan jaman, kebutuhan manusia akan komputer sangatlah tinggi . Berbagai aktivitas manusia sekarang mulai mengarah kepada penggunaan komputer. Kalo kita cari artinya, komputer itu adalah alat yang digunakan untuk melakukan pengolahan data. Kalau dari perangkatnya sendiri, komputer terdiri dari perangkat keras (Hardware) dan perangkat lunak (Software). Perangkat keras yang penting dalam komputer salah satunya adalah CPU atau Central Processing Unit. Penggunaan komputer haruslah sesuai dengan komponen komputer itu sendiri, kadang kala komputer diberikan beban kerja berlebihan sehingga menyebabkan panas berlebihan akibat pemakaian berlebihan tersebut. Panas yang mengganggu kinerja komputer ini harus segera di keluarkan, karena kalau dibiarkan bisa merusak perangkat komputer lainnya [1].

Alat yang digunakan untuk pendinginan komputer ini dikenal dengan nama sistem pendinginan komputer. Jadi alat ini berfungsi membuang panas dari komputer tersebut. Salah satu pendingin konvensional adalah pendinginan menggunakan kipas (fan). Namun semakin berkembangnya ilmu pengetahuan, pendinginan CPU khususnya laptop menggunakan fan sudah mulai ditinggalkan dengan alasan bentuk yang kurang compact, berisik dan mudah berdebu. $[2,3]$.Berdasarkan uraian mengenai pendinginan diatas maka penggunaan komputer harus memperhatikan sistem pendingin pada CPU yang nantinya akan membantu mempertahankan kinerja dari CPU tersebut.

Penggunaan pipa kalor di era sekarang ini merupakan sebuah alternative baru dalam pendinginan komputer[4]. Pipa kalor dapat diartikan sebagai alat penukar kalor yang menggunakan prinsip dua fasa serta bersifat pasif yakni dalam sirkulasi fluida kerja selama proses perpindahan kalor hanya memanfaatkan tekanan kapilaritas dari sumbu kapiler dan tidak menggunakan energi tambahan berupa energi listrik. Pipa kalor ini bertugas menyerap panas dari CPU tersebut kemudian panas tersebut dikeluarkan ke lingkungan sekitar, sehingga panas dalam CPU ini tidak mengganggu kinerja dari komputer [5]. Telah banyak penelitian mengenai pipa kalor telah dilakukan oleh Putra., dkk. yang salah satunya mengenai penggunaan pipa kalor sebagai pendingin CPU [6-11]. Pengembangan pun mulai dilakukan yang mengarah kepada peningkatan kinerja yang dibarengi dengan pengecilan ukuran dimensi dari produk teknologi tersebut [12]. Kinerja heat pipe yang optimal dapat menyebabkan peningkatan kalor dari sumber kalor dan di buang di bagian kondensor lumayan besar, temperatur yang di buang dibagian kondensor bisa mencapai $50^{\circ} \mathrm{C}-60^{\circ} \mathrm{C}$ [13].

Dalam mengatasi permasalahan panas yang biasa terjadi pada CPU, penulis kali ini akan mencoba melakukan penelitian mengenai "Pengaruh Single Double Kondensor Cascade Straight Heat pipe Terhadap Penurunan Temperatur Kerja" yang nantinya diharapkan dari penelitian ini didapatkan hasil yang optimal untuk penurunan panas pada CPU.

\section{METODE}

Metode yang digunakan adalah metode eksperimental. Metode pertama yang dilakukan yaitu proses pengujian terhadap obyek dengan variabel dengan yang diberi perlakuan tertentu. Penelitian dimulai dengan mempelajari literature mengenai heat pipe khususnya mengenai cascade straight heat pipe, faktor yang mempengaruhi kerja heat pipe, dan persiapan alat dan bahan yang dipakai dalam penelitian ini.

Tahap dilanjutkan dengan mendesain alat Cascade Straight Heat pipe. Pembuatan diawali dengan mencari straight heat pipe di pasaran. Setelah mendapat straight heat pipe yang telah di sesuaikan dengan desain awal maka bisa dilanjutkan ke tahap selanjutnya. Tahanp selanjutnya yaitu pembentukan sesuai desain. Pada saat pembentukan dilakukan secara hati-hati agar fluida dalam heat pipe tidak terjepit akibat lekukan pada heat pipe. 
Tahap dilanjutkan dengan melakukan pengujian temperatur kerja plat simulator, single dan double kondensor pada cascade straight heat pipe. Pada tahap ini pengujian dilakukan dengan memanaskan bagian evaporator heat pipe dengan alat pelat pemanas. Selama pengujian hasil kana terus diamati. Ada beberapa pembebanan yang digunakan dalam penelitian ini dengan maksud mendapatkan banyak variasim sehingga variasi tersebut bisa dibandingkan untuk dilanjutkan ke tahap analisa pengujian.

\subsection{Preparasi Desain Cascade Straight Heat Pipe}

Single cascade straight heat pipe dibentuk dari 2 buah straight heat pipe yang saling ditumpuk. Bagian evaporator 2 dari straight heat pipe kedua ditempelkan pada bagian kondensor dari straight heat pipe yang pertama. Sehingga nantinya evaporator straight heat pipe akan direkatkan pada kondensor straight heat pipe pertama menggunakan penjepit yang terbuat dari plat alumunium. Untuk dimensi atau ukuran dari single cascade straight heat pipe bisa dilihat pada gambar diatas.

Double cascade straight heat pipe dibentuk dari 3 buah straight heat pipe yang saling ditumpuk. Hampir sama dengan single cascade straight heat pipe, hanya saja ditambahkan lagi satu straight heat pipe pada bagian kondensor heat pipe tingkat satu. Sehingga ada 2 evaporator yang di tumpuk pada bagian kondensor heat pipe tingkat pertama. Untuk dimensi dan ukuran bisa dilihat pada gambar diatas.

\subsection{Skematik Pengujian}

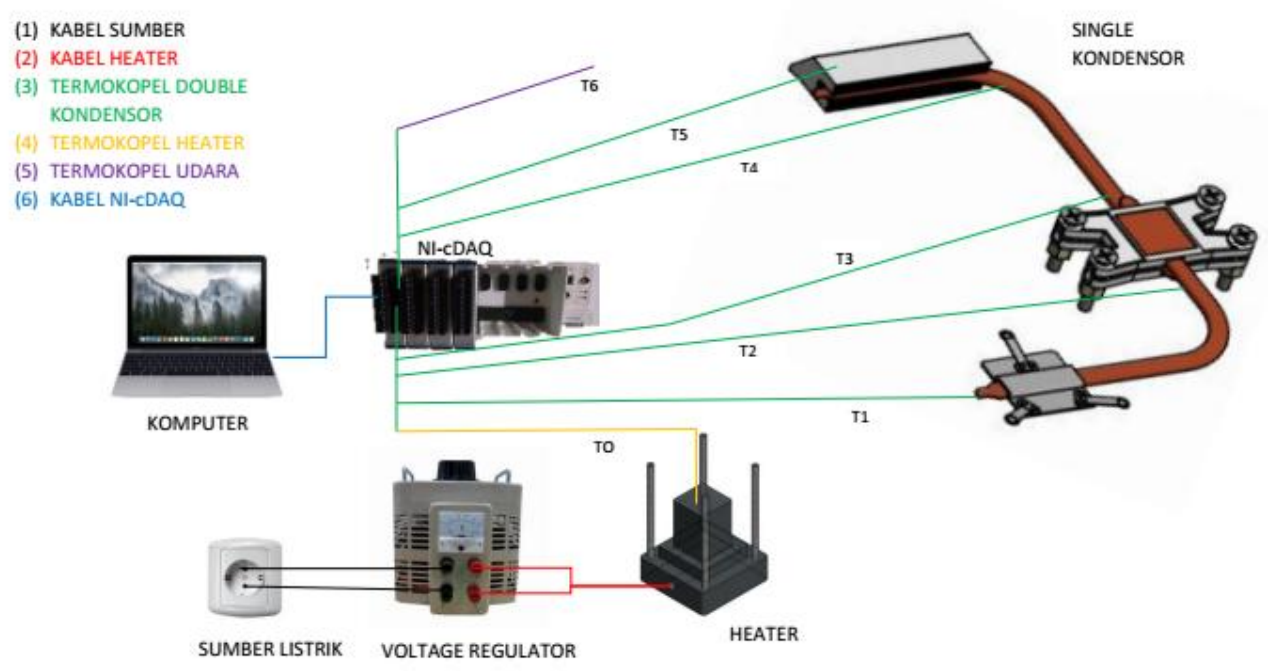

Gambar 4. Skematik pengujian single cascade straight heat pipe

Untuk mendapatkan hasil pengukuran maka kinerja sistem pendinginan cascade straight heat pipe diamati dengan meletakan 7 thermocouple tipe-K pada kondensor tunggal dan 10 thermocouple tipe-K pada double kondensor yang nanti hasilnya bisa diamati melalui komputer. 


\section{HASIL DAN PEMBAHASAN}

\subsection{Hasil Pengujian Temperatur Kerja}

Pada pengujian temperatur kerja akan diberikan 5 variasi yang berbeda dengan tujuan mensimulasikan keadaan CPU pada saat beroperasi. Variasi watt yang diberikan yaitu 10 watt, 20 watt, 30 watt, 40 watt dan 48 watt. Variasi watt dilakukan hingga masing-masing variasi mendapatkan kondisi steady state. Adapun hasil pengukuran masing-masing variasi untuk temperatur kerja plat simulator yang ditampilkan dalam tabel sebagai berikut :

Tabel 1 Tabel Variasi Pengujian Temperatur Kerja

\begin{tabular}{ccccc}
\hline VARIASI & $\begin{array}{c}\text { WAKTU } \\
(\mathbf{d e t i k})\end{array}$ & $\begin{array}{c}\text { PLAT } \\
\text { SIMULATOR } \\
\text { BAWAH }\left({ }^{\circ} \mathbf{C}\right)\end{array}$ & $\begin{array}{c}\text { PLAT } \\
\text { SIMULATOR } \\
\text { ATAS }\left({ }^{\circ} \mathbf{C}\right)\end{array}$ & $\begin{array}{c}\text { UDARA } \\
\left({ }^{\circ} \mathbf{C}\right)\end{array}$ \\
\hline 10 WATT & 15591 & 55.448 & 51.015 & 24.564 \\
20 WATT & 12020 & 79.032 & 70.119 & 25.875 \\
30 WATT & 18258 & 104.415 & 91.511 & 24.084 \\
40 WATT & 14192 & 113.389 & 95.200 & 25.706 \\
48 WATT & 13042 & 149.697 & 129.397 & 25.875 \\
\hline
\end{tabular}

\subsection{Hasil Pengujian Kondensor Cascade Straight Heat Pipe}

Pengujian pada temperatur single kondensor akan diberikan 5 variasi watt yang berbeda dengan tujuan mensimulasikan keadaan CPU pada saat dihidupkan yang nantinya cascade straight heat pipe single kondensor akan mendinginkan temperatur kerja tersebut. Variasi watt yang diberikan yaitu 10 watt, 20 watt, 30 watt, 40 watt dan 48 watt. Data pengujian single kondensor ini meliputi bagian atas plat simulator, 2 evaporator, 2 kondensor, heatsink dan udara.

Pengujian pada temperatur double kondensor akan diberikan 5 variasi watt yang berbeda dengan tujuan mensimulasikan keadaan CPU pada saat dihidupkan yang nantinya cascade straight heat pipe single kondensor akan mendinginkan temperatur kerja tersebut. Variasi juga sama dengan single kondensor. Data yang diambil dalam pengujian double kondensor ini meliputi bagian atas plat simulator, 3 evaporator, 3 kondensor, 2 heatsink dan udara.

\subsection{Analisa Hasil Pengujian}

Berdasarkan hasil pengujian yang telah dilakukan terhadap pendinginan menggunakan cascade straight heat pipe yang didapatkan hasil bahwa cascade straight heat pipe sangat memberikan dampak pada penurunan temperatur kerja. Data hasil penurunan tersebut bisa dilihat dalam gambar 6 dibawah. 


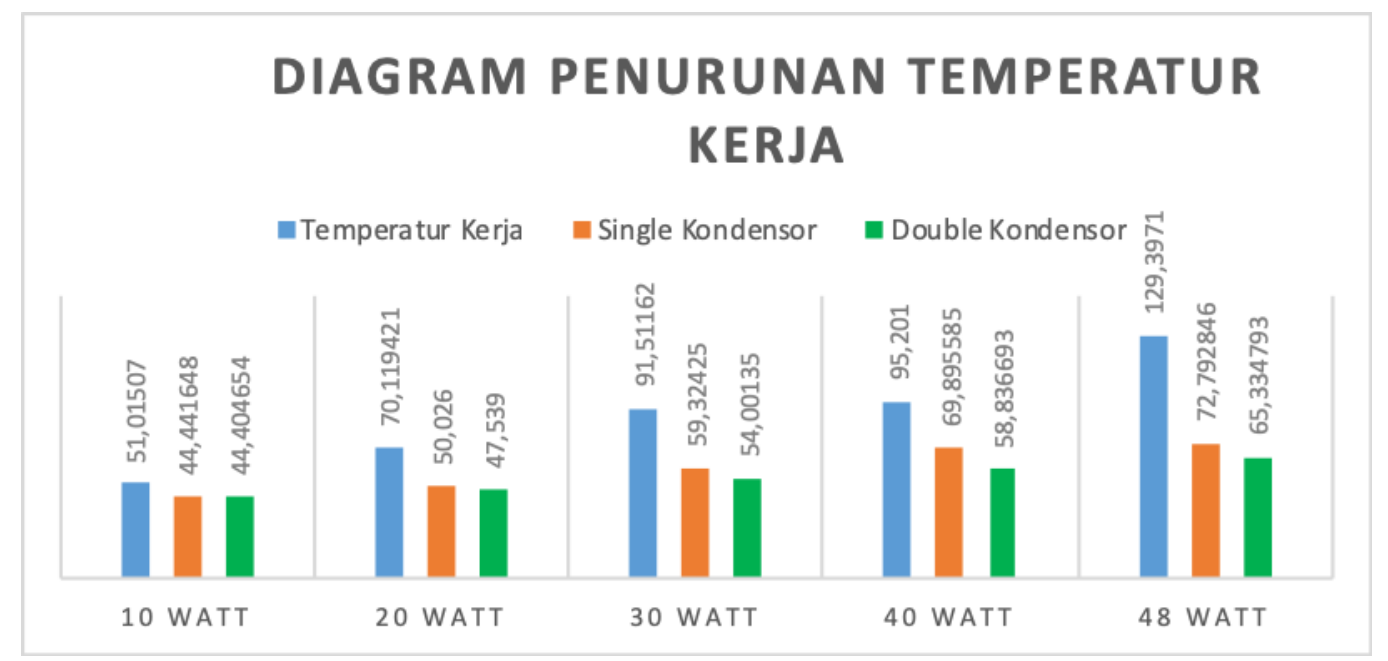

Gambar 6 Diagram Penurunan Temperatur Kerja

Ini disebabkan karena cascade straight heat pipe double kondensor memiliki hambatan termal yang lebih kecil dibandingkan cascade straight heat pipe single kondensor. Hambatan termal pada cascade straight heat pipe dihitung berdasarkan kondisi temperatur evaporator dengan temperature pada bagian kondensor terhadap pembebanan yang diberikan [14].

Hambatan panas akan semakin kecil pada peningkatan pembebanan atau penambahan Q. selain itu semakin besar $\Delta \mathrm{T}$ juga akan memperkecil hambatan panas. Hal inilah yang merupakan karakteristik dari heat pipe tersebut [15]. Hambatan termal yang kecil inilah yang menyebabkan reduksi panas pada bagian evaporator menjadi lebih besar. Selain itu sistem cascade straight heat pipe double kondensor memiliki alur sirkulasi pendinginan yang lebih panjang dibandingkan cascade straight heat pipe single kondensor. Panas pada sistem cascade straight heat pipe double keluar dari kondensor pertama tidak langsung dilepas ke lingkungan melainkan diserap kembali oleh evaporator 2 dan 3 sehingga sistem pendinginan berlanjut lagi di evaporator 2 dan 3 . Setelah didinginkan di tingkatan 2 dan 3 inilah, panas baru dilepaskan ke lingkungan melalui kondensor 2 dan 3. Dua hal inilah yang menyebabkan penurunan bisa terjadi signifikan pada sistem pendingin berbasis cascade straight heat pipe.

\section{SIMPULAN}

Dari pengujian dapat ditarik beberapa kesimpulan sebagai berikut :

1. Berdasarkan pemakaian single dan double kondensor pada sistem pendinginan CPU berbasis cascade straight heat didapatkan hasil penurunan yang sangat signifikan, hingga $57,6^{\circ} \mathrm{C}$ atau $44 \%$ untuk yang single kondensor dan $64,06^{\circ} \mathrm{C}$ atau $49 \%$ untuk double kondensor.

2. Untuk pembebanan rendah yaitu 10 watt penurunan belum terlalu signifikan. Untuk pembebanan 10 watt didapatkan hasil penurunan $6,57^{\circ} \mathrm{C}$ untuk yang single kondensor dan $6,6^{\circ} \mathrm{C}$ untuk double kondensor. Pembebanan 20 watt didapatkan penurunan $20,09^{\circ} \mathrm{C}$ untuk single kondensor dan $22,58^{\circ} \mathrm{C}$ untuk double kondensor. Pembebanan 30 watt didapatkan penurunan $32,19^{\circ} \mathrm{C}$ untuk single kondensor dan $37,51^{\circ} \mathrm{C}$ untuk double kondensor. Pembebanan 40 watt didapatkan penurunan $25,31^{\circ} \mathrm{C}$ untuk single kondensor dan $36,37^{\circ} \mathrm{C}$ untuk double kondensor. Pembebanan maksimal yaitu 48 watt didapatkan penurunan $57,6^{\circ} \mathrm{C}$ untuk single kondensor dan $64,06^{\circ} \mathrm{C}$ untuk double kondensor. 


\section{Ucapan Terima kasih:}

Terima kasih diucapkan kepada Kementerian Riset Teknologi dan Pendidikan Tinggi dan Lembaga Penelitian dan Pengabdian Kepada Masyarakat Universitas Udayana atas dukungan dana melalui skema Hibah Penelitian Terapan Unggulan perguruan Tinggi (PTUPT)-2019.

\section{Daftar Pustaka}

[1] Mujaya, I K. J. 2015. Pengaruh Penggunaan Pipa Kalor Bertingkat Terhadap Temperatur Kerja CPU dan Lingkungan di Sekitar Kondensor. Fakultas Teknik. Universitas Udayana

[2] Elnaggar, Mohamed H.A. 2013. Numerical Investigation of Characteristics of Wick Structure and Working Fluid of U-shape Heat Pipe for CPU Cooling, Engineering Department, Palestine Technical College

[3] Putra, Nandy, Aziz O, Idam Bariyanto, Fery Yusivar. Penggunaan Heatsink-Fan Sebagai Pendingin Sisi Panas Elemen Peltier Pada Pengembangan Vaccine Carrier. JURNAL TEKNOLOGI, Edisi No. 1. Tahun XXI, Maret 2007, 24-31 ISSN 0215-1685.

[4] Putra, N. \& Septiadi, W. N. 2014. Teknologi Pipa Kalor Teori, Desain dan Aplikasi. Jakarta: Departemen Teknik Mesin Universitas Indonesia.

[5] I. Mudawar. (2001). Assessment of high-heat-flux thermal management schemes. Components and Packaging Technologies, IEEE Transactions on, vol. 24, pp. 122141, 2001.

[6] Nandy Putra. Nano Teknologi: Pengembangan Potensi Nanofluida Sebagai Fluida Kerja Alternatif. ( 2003).

[7] Putra, Nandy, Wayan Nata Septiadi, Rosari Saleh, Rardi Artono Koestoer, and Suhendro Purbo Prakoso. "The Effect of CuO-Water Nanofluid and Biomaterial Wick on Loop Heat Pipe Performance." In Advanced Materials Research, 875, (2014). 356-361.

[8] Saleh, R., Putra, N., Wibowo, R. E., Septiadi, W. N., Prakoso, S. P. Titanium dioxide nanofluids for heat transfer applications. Experimental Thermal and Fluid Science, 52, (2014).19-29.

[9] Putra, N et al., "Application of Al2O3 Nanofluid on Sintered Copper-Powder Vapor Chamber for Electronic Cooling", Advanced Materials Research, Vol. 789, pp. 423-428, 2013.

[10] Putra, N., Septiadi, W. N., Rahman, H., Irwansyah, R. (2012). Thermal performance of screen mesh wick heat pipes with nanofluids. Experimental Thermal and Fluid Science, vol.40, pp.10-17.

[11] R. Chein and G. Huang. (2004). Thermoelectric cooler application in electronic cooling. Applied Thermal Engineering, vol. 24, pp. 2207-2217.

[12] Wayan Nata Septiadi, I Gede Putu Agus Suryawan, I Ketut Gede Wirawan, I Komang Jana Mujaya, Muchamad Rizal Sugiono Putu Wardana. Karakterisasi Kinerja Pipa Kalor Bertingkat dengan Wick Screen Mesh untuk Pendingin CPU. Prosiding KNEP VI ISSN 2338-414X (2015) 193-199.

[13] Vasiliev, Leonard L. 2005. Heat Pipes in Modern Heat Exchangers. Belarus Minsk: Russia.

[14] Wayan Nata Septiadi, I Gusti Ketut Sukadana, I Ketut Astawa, Cahyo Sudarmo, I Nyoman Swar Raditya M. Hambatan Termal Pipa Kalor Bertingkat Dengan Fluida Kerja Hybrid Nanofluid Al2O3-CuO-Air, SNTTM XV, 2016, 490-497

[15] D. Reay, p. Kew, Heat Pipe Teory, desain and application, $5^{\text {th }}$ edition, Elsevier, 2006 